\title{
Infiltration behaviour of dike covers made of dredged material on the Rostock Research dike
}

\author{
Tim Jurisch*, Stefan Cantré, and Fokke Saathoff \\ University of Rostock, Chair of Geotechnics and Coastal engineering, 18059 Rostock, Germany
}

\begin{abstract}
The knowledge about the infiltration behaviour of a dike body is an important issue in dike design and flood risk assessment. To reduce the risk of stability failures during flood events, the infiltration rate of a dike should be kept low and the elapsing time to reach the saturated steady state should be long. A number of full-scale physical flood simulation experiments on the Rostock research dike, on which different processed dredged materials were applied in the dike body (cover layers in particular) showed that the infiltration time and rate is much higher as can be expected from comprehensive laboratory test data. To obtain information about the unsaturated/saturated hydraulic soil properties of the installed dredged materials in situ, an automatic multi-objective model calibration method for a minimizing problem is used to reduce the residuals between simulated and observed time series (hydraulic head pressure, suction pressure and rate budget). The measured suction pressure time series of these physical experiments lets us suppose, that it is not possible to simulate the suction pressure behaviour of the installed dredged material using RICHARD's unsaturated flow equation with a proper water retention function and unsaturated flow conductivity. It seems that the hysteresis effects are negligibly small and the hydraulic behaviour is governed by the inter-aggregate pore structure. In the paper, different back-calculation methods to fit the soil hydraulic parameters to the full-scale measurements are discussed and compared a proposal for the evaluation of the data is provided.
\end{abstract}

\section{Introduction}

Climate change challenges make a rethinking in flood defence strategy necessary. As one part of these efforts, dried fine-grained dredged materials from the SouthBaltic area were investigated for their suitability to replace standard dike construction materials [1]. Dredged materials arise in huge amounts e.g. during maintenance works in harbours and water ways. After dredging, materials with a large fine fraction need to be put on land for beneficial use or disposal, depending on their contamination level. Non-contaminated materials may be used as construction material, e.g. in landfill restoration [2], in filling former mining areas, or in landscaping and agriculture [3]. The application of finegrained dredged material as replacement for dike cover materials has a comparatively young history. Although there is some experience with dredged materials used in dike construction in Germany, there is still a lack of knowledge about the infiltration behaviour of these materials and about their performance regarding seepage during flood events.

A number of full-scale physical flood simulations have been conducted on the Rostock research dike in 2013 and 2014 in order to investigate the hydraulic material performance of different dredged materials $[1,4]$. The research is divided in two parallel dikes (east, west) and three polders (P1-P3) to be filled with water separately (Fig. 1). For the eastern cross-sections the test results show, that the hydraulic head pressure within the dike body increased fast and the drain runoff was high. The issue of this paper is to discuss the infiltration behaviour of fine-grained dredged material with high organic contents. The finite-element software FEFLOW [5] is used to simulate the infiltration and observation data (moisture, suction and runoff measurements) is used for comparison. A pre-calibration is performed with the multi-objective genetic evolutionary algorithm AMALGAM [6] and these results are discussed regarding hysteresis effects on four soil water retention curves (SWRCs) and their unsaturated conductivity pedo-transfer functions.

\section{Research dike and material properties}

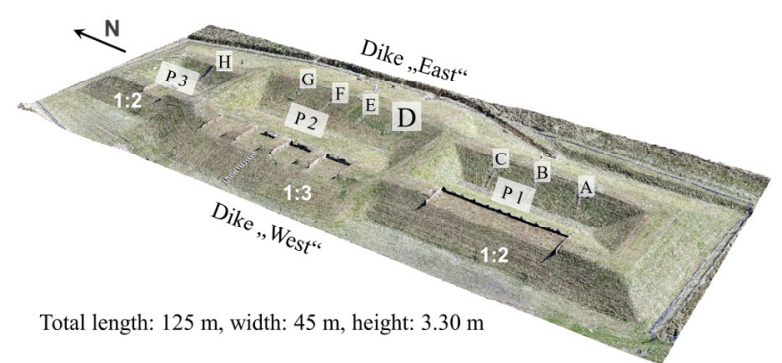

Fig. $13 \mathrm{D}$ view of the Rostock research dike with polders P1P3 and cross-sections A-H (different material combinations) 


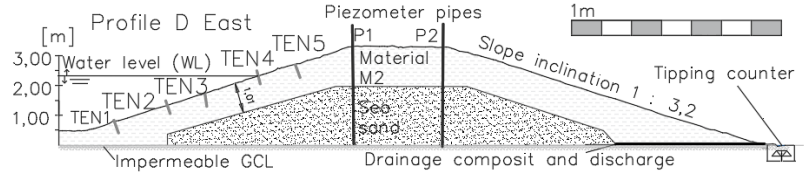

Fig. 2 Cross-section D of dike "East".

Fig. 1 shows the general setup of the Rostock research dike with the polder structure to simulate flood (by filling according to a particular hydrograph) and overtopping (by filling beyond the lower crest sections on the western dike). It is divided in eight hydraulically separated cross-sections (A-H), with varying slope inclination, material combinations, and installation technology [1,7]. The considerations of this study exemplarily refer to cross-section D (Fig. 2) on dike "East" with respect to experimental data which was obtained during the period of 26 June to 7 July 2013 [4].

In cross-section D "East", five tensiometers (type T151, UGT GmbH) were installed within the cover layer in varying depths of $0.2 \mathrm{~m}$ to $0.5 \mathrm{~m}$ below the surface to obtain observation data about the absorption and desorption characteristics. The hydraulic head inside the dike core was continuously recorded using a pressure probe (Type 46x, Keller AG) in piezometer pipe P1 with a sampling rate of $1 \mathrm{~Hz}$ (recording $15 \mathrm{~min}$ interval average values) and discontinuously using manual water level gauges in pipe P2. The seepage was collected in a horizontal drain and recorded with a REED sensor equipped tipping counter (UGT GmbH, $100 \mathrm{ml}$ per tipping, max. $8.3 \mathrm{E}-5 \mathrm{~m}^{3} / \mathrm{s}$ ). The cover layer is made of the dredged material M2. It is classified as a fine-grained sandy silt with a high total organic content (TOC). In the dike core, a poorly-graded fine sea sand is installed. The cover layer of cross-section D was built using $0.3 \mathrm{~m}$ thick layers with subsequent roller compactions perpendicular to the longitudinal dike axis [7].

Table 1. Properties of dredged material M2 and sea sand [1]

\begin{tabular}{|lll|l|l|}
\hline Property & Standard & Unit & M2 & Sand \\
\hline $\begin{array}{l}\text { Grain sizes } \\
\text { (s / si / cl) }\end{array}$ & ISO 11277 & {$[\%]$} & $45 / 33 / 22$ & $98 / 2 / 0$ \\
TOC & ISO 10694 & {$[\%]$} & $5 \ldots 6$ & 0 \\
$K_{s(\text { dist. })}$ & DIN 18128 & {$\left[\mathrm{~ms}^{-1}\right]$} & $8 \mathrm{E}-10 \ldots 5.2 \mathrm{E}-$ & $8.6 \mathrm{E}-5$ \\
$K_{s(\text { undist.) }}$ & DIN 18128 & {$\left[\mathrm{md}^{-1}\right]$} & $4 \mathrm{E}-8 \ldots 6 \mathrm{E}-8$ & - \\
$\begin{array}{l}\text { Pore void } n \\
\text { Density }\end{array}$ & - & {$[\%]$} & $59 \ldots 66$ & 40 \\
Dry density & - & {$\left[\mathrm{gcm}^{-3}\right]$} & $1.48 \ldots 1.54$ & 1.8 \\
\hline
\end{tabular}

Table 2. Detailed laboratory results of seven SWRCs of M2 desorption curve (ceramic plate method) [1]

\begin{tabular}{|l|llllllll|}
\cline { 2 - 9 } \multicolumn{1}{c|}{} & \multicolumn{8}{c|}{$\boldsymbol{\Theta}_{\text {vol }}[\mathbf{1}]$} \\
\hline No. & 0 & -0.3 & -2 & -6 & -13 & -30 & -60 & -1500 \\
\hline $\mathbf{1}$ & 0.56 & 0.54 & 0.54 & 0.53 & 0.51 & 0.50 & 0.48 & 0.16 \\
$\mathbf{2}$ & 0.57 & 0.52 & 0.52 & 0.52 & 0.51 & 0.50 & 0.47 & 0.16 \\
$\mathbf{3}$ & 0.62 & 0.56 & 0.55 & 0.53 & 0.48 & 0.47 & 0.44 & 0.14 \\
$\mathbf{4}$ & 0.58 & 0.51 & 0.51 & 0.51 & 0.48 & 0.48 & 0.46 & 0.16 \\
$\mathbf{5}$ & 0.58 & 0.53 & 0.53 & 0.52 & 0.51 & 0.50 & 0.48 & 0.16 \\
$\mathbf{6}$ & 0.62 & 0.55 & 0.55 & 0.55 & 0.53 & 0.51 & 0.50 & 0.14 \\
$\mathbf{7}$ & 0.68 & 0.54 & 0.53 & 0.53 & 0.51 & 0.48 & 0.47 & 0.14 \\
\hline \hline ØM2 & 0.59 & 0.54 & 0.53 & 0.53 & 0.51 & 0.49 & 0.47 & 0.15 \\
\hline
\end{tabular}

Geotechnical and geohydraulic material characteristics of M2 and sand were investigated in an earlier research project [1] and are summarised in Tab. 1. The SWRCs of seven undisturbed M2 soil samples (average ØМ2) have been determined with the desorption method using ceramic plates (Tab. 2 [1]). According to the matrix potential concept [13], the suction pressure is defined as a negative value to indicate unsaturated soil conditions (definitions differ between disciplines).

\section{Method}

The present study aims to investigate the infiltration behaviour of the Rostock research dike in saturated and unsaturated conditions. Therefore, a FEFLOW [5] model was set up based on the spatial information of crosssection D (Fig. 2). In order to simulate the saturated/ unsaturated flow, the RICHARD's equation is used in transient mode and vertical planar view. Hydraulic material properties obtained from laboratory testing (Tab. 1) are used for primary orientation as it is known, that material properties may considerately differ to the respective properties determined on site. Therefore, a pre-calibration is conducted using a multi-objective genetic-evolutionary algorithm "AMALGAM" [6] to find the global minima within realistic parameter ranges. Three objective functions (OBF I-III) are used to clarify the physical meaning of hydraulic head data (P1, P2), drainage runoff data (Drain) and suction pressure data (TEN 1-5) (Fig. 3). All OBF's are defined as the deviation between observation and simulation data using the mean square error MSE.

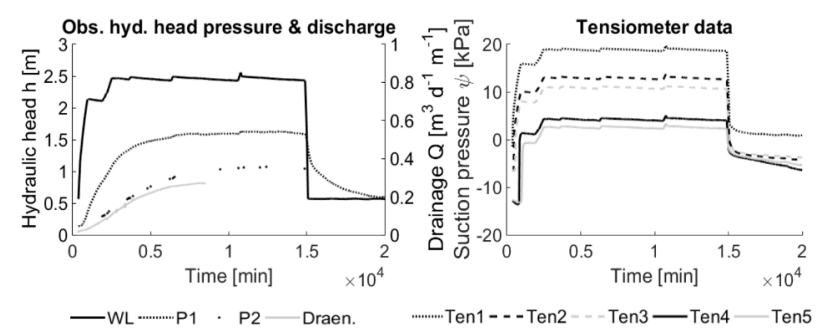

Fig. 3 Observation data

Table 3. Available SWRC functions in FEFLOW

\begin{tabular}{|c|c|c|c|}
\hline & $S_{e}(\psi)$ & $K_{r}(\theta)$ & M. \\
\hline \multirow{6}{*}{$\mathrm{S}_{\mathrm{e}}=$} & $\begin{cases}{\left[1+\left(-a \psi_{m}\right)^{n}\right]^{-(1-1 / n)}, \psi_{m}} & <0 \\
1_{z} & \psi_{m} \geq 0\end{cases}$ & $K_{r}(\theta)=K_{\varepsilon} S_{\varepsilon}^{l}\left[1-\left(1-S_{\varepsilon}^{1 / m}\right)\right]$ & I \\
\hline & $\left\{\begin{aligned} & {\left[1+\left(-a \psi_{m}\right)^{n}\right]^{-m}, } \psi_{m}<0 \\
& 1, \psi_{m} \geq 0 \\
&\end{aligned}\right.$ & $K_{r}(\theta)=S_{e}^{\delta}$ & II \\
\hline & $\begin{cases}\frac{1}{1+(-L \psi)^{\beta} / \alpha}, & \psi_{m}<0 \\
1_{m} & \psi_{m} \geq 0\end{cases}$ & $K_{r}(\theta)= \begin{cases}\frac{1}{1+(-L \psi)^{D} / A} & \psi_{\mathrm{ma}}<0 \\
1 & \psi_{m} \geq 0\end{cases}$ & III \\
\hline & $\begin{cases}\frac{1}{\mid \alpha \psi \psi^{M^{x}}} & \psi_{m}<-1 / a \\
1_{s} & \psi_{m} \geq-1 / \alpha\end{cases}$ & $K_{r}(\theta)=\xi_{\theta}^{\delta}$ & IV \\
\hline & $\begin{cases}\exp \left(\alpha\left(\psi_{m}-\psi_{a}\right)\right), \psi_{m} & <\psi_{a} \\
1, & \psi_{m} \geq \psi_{a}\end{cases}$ & $K_{r}(\theta)-S_{\mathrm{z}}$ & V \\
\hline & $\left\{\begin{array}{lr}0 ; & \psi \leq \psi_{t} \\
\frac{\psi\left(\psi-\psi_{t}\right)}{\left(\psi-\psi_{a}\right)} & \psi_{\mathrm{r}} \leq \psi<\psi_{a} \\
1 & \psi_{a}<\psi\end{array}\right.$ & $K_{r}(\theta)-S_{\varepsilon}$ & VI \\
\hline
\end{tabular}

Model: I VANGENUChTEN-MUALEM, II Mod. VAN GeNUChTEN, 
Within the unsaturated flow operation mode, FEFLOW provides six pedo-transfer functions that describe the relationship between the suction pressure and the effective saturation $S_{e}(\psi)$ as well as effective saturation and relative conductivity $K_{r}(\theta)$ according to Tab. 3 .

It was not known which of these SWRC-functions is able to describe the unsaturated flow and suction behaviour of M2. Hence, each function is fitted to the lab data (Tab. 2) in order to find the best fit model. For this purpose, two approaches have been tested: the FEFLOW fitting tool and a MATLAB script that follows the general procedure of the RetC software [8].

There is no SWRC laboratory data available that describes the saturated/unsaturated flow of the applied sand inside the dike core of the Rostock research dike. To work around this, fitting parameters were taken from RetC data base, because a) the sea sand is very homogenous and a significant spread of material properties is not expected; b) the infiltration behaviour is primarily affected by the material properties of the cohesive cover layer and c) the fine adjustments are made in the precalibration.

It is known that hysteresis effects may affect the infiltration of dike bodies considerably [9-11]. The process of desorption is then faster than the infiltration process and the suction pressure for an equal water content is lower with desorption.

Because there is no information about the absorption characteristics of the dredged material, SWRC fitting parameters (desorption) are determined using a model pre-calibration with AMALGAM. If suitable model fittings would be found, the simulation would be subsequently repeated with SWRC parameters that account for the hysteresis. It is assumed that the hysteresis of M2 shows a comparable behaviour as clay soils e.g. in [12] and the SWRC fitting parameters are substituted for absorption and desorption respectively. Regarding the VANGENUCHTEN-MUALEM model, the curve fitting parameter of the desorption curve $\alpha_{d}$ is assumed to be two times larger than the absorption curve parameter $\left(\alpha_{d}=2 \alpha_{a}\right)[9,14]$ if an enveloping hysteresis curve is desired to clarify the maximum effect.

\section{Results}

Fitting results according to the available FEFLOW SWRC models are listed in Tab. 4. Apart from the BROOKS \& COREY model (IV), in all approaches more or less acceptable fittings could be found for an average value ØM2 (Tab. 2) that acceptably represent the desorption SWRC with sum of squared residuals SSR $<5$ E-04. This criterion seems to be sufficient as the individual moisture content $\theta_{v o l}$ of the investigated soil samples varies in a range of $\pm 2 \%$. According to [14], the determination of the SWRC using laboratory test methods is difficult and larger variations and errors are a general problem [14], a representable accuracy should be generally doubted; especially because the heterogeneities of the materials in the field are expected to be much more relevant.
The fitting with the Modified VANGENUCHTEN model (II) generally showed better results than that with the MuALEM-VANGENUCHTEN model (I). The reason is an additional fitting of parameter $m$ (Tab. 3 M. II) in model II. However, this goes along with an increasing variance of the other parameters $\left(a, n, \theta_{r}, \theta_{s}\right)$, indicating an overfitting. It is not clear which of these parameter sets are representative for the unsaturated flow simulation in the present study and therefore an application of the Modified VAN GENUCHTEN is not considered further.

Fig. 4 illustrates the SWRC fitting for selected models. Results for the model pre-calibration are listed in Tab. 5 to 7 together with the consideration of hysteresis effects. Lines No. 1 to 3 contain the parameter combinations for the minimum of OBF I, II and III respectively, while line No. 4 contains the sum of OBF I and OBF II.

According to Tab. 5, it was possible to identify minima with the VANGENUCHTEN model for all three objectives (OBF I < 0.02; OBF II < 0.001; OBF III < 10) separately. However, no parameter set could be found in this pre-calibration (3000 model runs) that matches the minimum criterion for all three objectives at the same time. Furthermore, the parameter set of Tab. 5 No. 3 considerably differs from the others and indicates a different physical meaning.

Table 4. Results of SWRC parameter fitting using average values of dredged material M2 (Ø M2 from Tab. 2).

\begin{tabular}{|c|c|c|c|c|c|c|}
\hline M. & \multicolumn{3}{|c|}{ Fitting Parameter } & $\theta_{S}[1]$ & $\theta_{R}[1]$ & SSR \\
\hline I & $\alpha=0.106 \mathrm{~m}^{-1}$ & \multicolumn{2}{|c|}{$n=1.44$} & 0.53 & 0 & $3.84 \mathrm{E}-4$ \\
\hline II & $\begin{array}{l}\alpha= \\
0.003 \mathrm{~m}^{-1}\end{array}$ & $\begin{array}{l}n= \\
0.725\end{array}$ & $\begin{array}{l}m= \\
2.62\end{array}$ & 0.54 & 0 & $1.40 \mathrm{E}-4$ \\
\hline III & $\alpha=20.46$ & \multicolumn{2}{|c|}{$\beta=0.78$} & 0.54 & 0 & $4.53 \mathrm{E}-4$ \\
\hline IV & $\alpha=0.205 \mathrm{~m}^{-1}$ & \multicolumn{2}{|c|}{$n=0.48$} & 0.52 & 0.07 & $1.51 \mathrm{E}-3$ \\
\hline $\mathrm{V}$ & $\alpha=0.205 \mathrm{~m}^{-1}$ & \multicolumn{2}{|c|}{$\psi_{a}=-1.32 \mathrm{~m}$} & 0.53 & 0.14 & $5.89 \mathrm{E}-5$ \\
\hline VI & $\psi_{a}=-0.02 \mathrm{~m}$ & \multicolumn{2}{|c|}{$\Psi_{t}=-35.55 \mathrm{~m}$} & 0.53 & 0.15 & $2.35 \mathrm{E}-4$ \\
\hline
\end{tabular}

Model: I MuALEM-VANGENUCHTEN, II Mod. -VANGENUCHTEN, III HAVERKAMP, IV BROOKS \& COREY, V Exponential, VI Linear

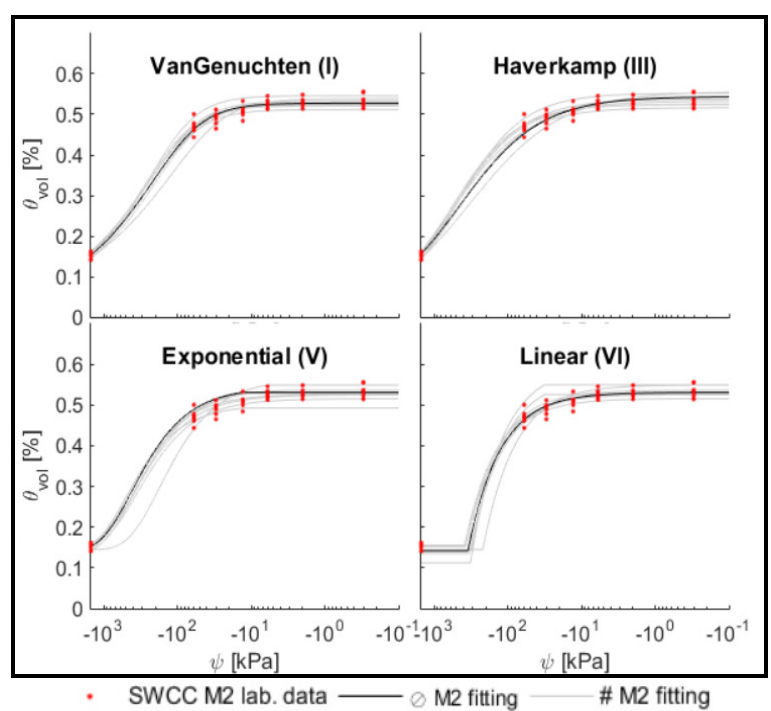

Fig. 4 Best fittings with the chosen SWRC for M2. 
Table 5. Pre-calibration results using the Mualem-VAnGenuChten function ( $m=1-1 / n)$ for the desorption characteristics.

\begin{tabular}{|c|c|c|c|c|c|c|c|c|c|c|c|c|c|c|c|c|}
\hline No & $\begin{array}{c}K_{s} \\
\text { Sand } \\
{\left[\mathrm{ms}^{-1}\right]}\end{array}$ & $\begin{array}{c}K_{s} \\
\mathrm{M} 2 \\
{\left[\mathrm{~ms}^{-1}\right]}\end{array}$ & $\begin{array}{c}n \\
\text { Sand } \\
{[1]}\end{array}$ & $\begin{array}{c}n \\
\mathrm{M} 2 \\
{[1]}\end{array}$ & $\begin{array}{c}S_{s} \\
\text { Sand } \\
{[1]}\end{array}$ & $\begin{array}{c}S_{s} \\
\text { M2 } \\
{[1]}\end{array}$ & $\begin{array}{c}S_{r} \\
\text { Sand } \\
{[1]}\end{array}$ & $\begin{array}{c}S_{r} \\
\mathrm{M} 2 \\
{[1]}\end{array}$ & $\begin{array}{l}V G \alpha \\
\text { Sand } \\
{\left[\mathrm{m}^{-1}\right]}\end{array}$ & $\begin{array}{c}V G \alpha \\
\text { M2 } \\
{\left[\mathrm{m}^{-1}\right]}\end{array}$ & $\begin{array}{c}V G n \\
\text { Sand } \\
{[1]}\end{array}$ & $\begin{array}{l}V G n \\
\text { M2 } \\
{[1]}\end{array}$ & $\begin{array}{l}\text { Drain } \\
{\left[\mathrm{m}^{2}\right]}\end{array}$ & $\begin{array}{l}\text { OBF I } \\
\text { MSE }\end{array}$ & $\begin{array}{l}\text { OBF II } \\
\text { MSE }\end{array}$ & $\begin{array}{c}\text { OBF III } \\
\text { MSE }\end{array}$ \\
\hline 1 & $2.19 \mathrm{E}-5$ & $1.85 \mathrm{E}-6$ & 0.43 & 0,65 & 0.97 & 0.83 & 0.05 & 0.31 & 1.18 & 0.63 & 3.76 & 4.36 & $2.69 \mathrm{E}-4$ & 0.013 & $4.27 \mathrm{E}-3$ & 41.04 \\
\hline 2 & $1.81 \mathrm{E}-5$ & $2.43 \mathrm{E}-6$ & 0.39 & 0.65 & 0.97 & 0.86 & 0.04 & 0.15 & 0.20 & 2.12 & 3.72 & 4.49 & $4.47 \mathrm{E}-5$ & 0.154 & $2.19 \mathrm{E}-5$ & 144.67 \\
\hline 3 & $8.10 \mathrm{E}-7$ & $9.65 \mathrm{E}-5$ & 0.39 & 0.65 & 0.95 & 0.99 & 0.03 & 0.20 & 0.10 & 4.62 & 3.77 & 1.01 & $2.79 \mathrm{E}-4$ & 2.081 & $5.91 \mathrm{E}-3$ & 5.73 \\
\hline 4 & $2.19 \mathrm{E}-5$ & $1.85 \mathrm{E}-6$ & 0.43 & 0.65 & 0.97 & 0.83 & 0.05 & 0.02 & 1.26 & 0.52 & 3.77 & 4.36 & $1.55 \mathrm{E}-4$ & 0,014 & $1,38 \mathrm{E}-3$ & 42,61 \\
\hline
\end{tabular}

Table 6. Summarized results repeating the models of Tab. 5 with substituted parameter for A) SWRC laboratory data and B) hysteresis assumptions.

\begin{tabular}{|l|c|c|c|c|c|c|}
\cline { 2 - 7 } \multicolumn{1}{c|}{} & \multicolumn{2}{c|}{ A - SWRC fitting (MSE) } & \multicolumn{2}{c|}{ B -Hysteresis (MSE) } \\
\hline No. & OBF I & OBF II & $\begin{array}{c}\text { OBS } \\
\text { III }\end{array}$ & OBF I & $\begin{array}{c}\text { OBF } \\
\text { II }\end{array}$ & $\begin{array}{c}\text { OBS } \\
\text { III }\end{array}$ \\
\hline 1 & 0,02 & $1.0 \mathrm{E}-2$ & 54.55 & 0.017 & $7.4 \mathrm{E}-3$ & 56.00 \\
\hline 2 & 0,92 & $2.3 \mathrm{E}-2$ & 53.60 & 0.748 & $1.5 \mathrm{E}-2$ & 52.86 \\
\hline 3 & 1,58 & $4.7 \mathrm{E}-1$ & 57.27 & 1.620 & $2.3 \mathrm{E}-1$ & 55.82 \\
\hline 4 & 0,09 & $6.0 \mathrm{E}-3$ & 53.37 & 0.022 & $3.9 \mathrm{E}-3$ & 54.00 \\
\hline
\end{tabular}

Table 7. Pre-calibration results using HAVERKAMP's function for the desorption characteristic.

\begin{tabular}{|c|c|c|c|c|c|c|c|c|c|c|c|c|}
\hline No. & $\begin{array}{c}K_{s} \\
\text { Sand } \\
{\left[\mathrm{md}^{-1}\right]}\end{array}$ & $\begin{array}{c}K_{s} \\
\mathrm{M} 2 \\
{\left[\mathrm{md}^{-1}\right]}\end{array}$ & $\begin{array}{c}n \\
\text { Sand } \\
{[1]}\end{array}$ & $\begin{array}{c}n \\
\text { M2 } \\
{[1]}\end{array}$ & $\begin{array}{c}S_{s} \\
\text { Sand } \\
{[1]}\end{array}$ & $\begin{array}{c}S_{s} \\
\text { M2 } \\
{[1]}\end{array}$ & $\begin{array}{c}S_{r} \\
\text { Sand } \\
{[1]}\end{array}$ & $\begin{array}{c}S_{r} \\
\text { M2 } \\
{[1]}\end{array}$ & $\begin{array}{c}H V \alpha \\
\text { Sand } \\
{[1]}\end{array}$ & $\begin{array}{c}H V \alpha \\
\text { M2 } \\
{[1]}\end{array}$ & $\begin{array}{c}H V \beta \\
\text { Sand } \\
{[1]}\end{array}$ & $\begin{array}{c}H V \beta \\
\text { M2 } \\
{[1]}\end{array}$ \\
\hline 1 & $8.22 \mathrm{E}-6$ & 0.17 & 0.38 & 0.60 & 0.97 & 0.90 & 0.19 & 0.24 & 33.62 & 3.00 & 26.65 & 13.05 \\
\hline 2 & $5.79 \mathrm{E}-7$ & 1.81 & 0.37 & 0.63 & 0.87 & 0.80 & 0.24 & 0.26 & 5.80 & 12.25 & 0.10 & 34.13 \\
\hline 3 & $1.62 \mathrm{E}-6$ & 2.47 & 0.43 & 0.61 & 0.92 & 0.80 & 0.12 & 0.07 & 26.22 & 10.89 & 27.56 & 20.75 \\
\hline 4 & $9.84 \mathrm{E}-6$ & 0.17 & 0.39 & 0.60 & 0.96 & 0.80 & 0.11 & 0.24 & 0.24 & 8.71 & 20.09 & 36.90 \\
\hline
\end{tabular}

\begin{tabular}{|l|c|c|c|c|c|c|c|c|}
\cline { 2 - 9 } \multicolumn{1}{c|}{ cont. } & $\begin{array}{c}H V A \\
\text { Sand [1] }\end{array}$ & $\begin{array}{c}H V A \\
\text { M2 [1] }\end{array}$ & $\begin{array}{c}H V B \\
\text { Sand [1] }\end{array}$ & $\begin{array}{c}H V B \\
\text { M2 }[1]\end{array}$ & $\begin{array}{c}\text { Drain } \\
{\left[\mathrm{m}^{2}\right]}\end{array}$ & $\begin{array}{c}\text { OBF I } \\
\text { MSE }\end{array}$ & $\begin{array}{c}\text { OBF II } \\
\text { MSE }\end{array}$ & $\begin{array}{c}\text { OBF III } \\
\text { MSE }\end{array}$ \\
\hline 1 & $9.61 \mathrm{E}-6$ & $4.16 \mathrm{E}-4$ & 70.56 & 6.52 & $4.99 \mathrm{E}-4$ & 0.012 & $2.80 \mathrm{E}-3$ & 37.03 \\
\hline 2 & $3.75 \mathrm{E}-4$ & $2,27 \mathrm{E}-4$ & 36.53 & 0.01 & $1.58 \mathrm{E}-5$ & 0.408 & $2,65 \mathrm{E}-5$ & 51.14 \\
\hline 3 & $2.16 \mathrm{E}-4$ & $1.16 \mathrm{E}-6$ & 82.65 & 82.31 & $1.76 \mathrm{E}-4$ & 0.260 & $1.31 \mathrm{E}-2$ & 11.59 \\
\hline 4 & $4.63 \mathrm{E}-6$ & $5.00^{\mathrm{E}}-4$ & 65.78 & 1.86 & $4.92 \mathrm{E}-4$ & 0.014 & $1.10 \mathrm{E}-3$ & 50.26 \\
\hline
\end{tabular}

The pre-calibrated model (Tab. 5) is simulated a second time and the SWRC fitting parameters are substituted by laboratory data (Tab. 4 I). The results are listed in Tab. $6 \mathrm{~A}$, showing a lower model fitting. The same results apply when the parameters are substituted by hysteresis parameters in order to consider the unsaturated infiltration in the wetting phase (Tab. $6 \mathrm{~B})$.

Using HAVERKAMP's model (4200 model runs), the pre-calibration shows similar results (Tab. 7). Objective minima were found for each function separately. A global solution that involves a single parameter set and matches for all three objectives at the same time could not be identified although this model allows an unconstrained fitting of $\operatorname{Kr}(\theta)$ using two additional fitting parameters $A$ and $B$ (Tab. 3 M II).

Both the linear and the exponential model functions assume a constrained relationship of $\operatorname{Kr}(\theta)=S_{e}$ (Tab.3 $\mathrm{V}, \mathrm{VI})$. Therefore, a compromise between the fitting of suction pressure and unsaturated flow conductivity is needed.

\section{Discussion}

Regarding the results in Tab 4, M2 shows an extraordinary suction behaviour that is indicated by $\alpha=0.106 \mathrm{~m}^{-1}$. This behaviour is indirectly confirmed in the precalibration where the best fittings are obtained using a value $\alpha<0.627 \mathrm{~m}^{-1}$. These assumptions are necessary in order to simulate the initial state condition of the dike model in which the saturation $S$ usually remains very high $(S>0.80 ; \psi>-15 \mathrm{kPa}$, Fig. 3$)$.

Compared to the RetC data base, this value is in best accordance with the minimum value of a mineral silty clay soil $\left(\alpha=0.5 \mathrm{~m}^{-1}\right)$. Similar experiences have been made with dredged material used as landfill site restoration layers [2] and in agriculture [3] in which the fine-grained fraction and the organic content improve the water budget performances. This confirms the experience of the observed permanently high moisture content when the research dike was constructed and is an explanation for the challenge to reach the optimum (Proctor) water content during this time with regard to compaction of the materials $[1,7]$.

According to Fig. 3, the tensiometers indicate no infiltration up to the moment the water level exceeds the sensor position. If the water level is exceeded, the cover layer changes almost immediately to the saturated state. From the laboratory data a delayed infiltration would be expected, however, such behaviour could not be observed. This is seen as an indicator for the presence of horizontal capillaries that are possibly build by an interaggregate pore system, plant roots, or cracks. It is also identified as the reason for the deviation in No. 1 \& 2 OBF I and OBF II in contrast to No. 3 OBF III (Tab. 5 and 7). The combination of a high $k_{s}$ value and a very low $\alpha$ value for M2 (e.g. Tab. 5 No. I) leads to an im- 
mediate reaction on the simulated suction pressure. In this case, the cover layer starts to saturate even for lower water levels. On the other hand, the best model fitting on tensiometer data OBF III is obtained using a combination of a sandy dike core with very low water permeability $\left(k_{s}=8.10 \mathrm{E}-7 \mathrm{~ms}^{-1}\right)$ and a permeable cover layer with $k_{s}=9.65 \mathrm{E}-5 \mathrm{~ms}^{-1}$ (Tab. 5 no. III). This causes a damming of infiltrating water on the interface and leads to a fast horizontal flow in the cover layer as observed by tensiometer data. However, this significantly increases the model error in OBF I and OBF II and is also not logical when compared to the actual earth construction with sand core and cohesive cover layer.

Empirical SWRCs refer to general assumptions of unimodal pore size distributions. Furthermore, it is well known that SWRCs are very sensitive to soil treatment such as compaction, ploughing methods or plant growth. The curves vary in seasonal fluctuations and may change with pedo-genetic processes if the soil texture and the pore voids are affected [13].

After installation, the degree of compaction (DOC compared to the Proctor density) for material M2 was determined to values between $70 \%-85 \%$ [7]. Because effects of compaction on the M2 soil texture und the infiltration behaviour are unknown, additional investigations have been undertaken with the double-ring infiltration method (DIN 19683) using methylene blue as due colour. The results of these in-situ tests in depts of $0.1 \mathrm{~m}$ to $0.4 \mathrm{~m}$ below surface show that the in-situ infiltration rate of $2.88 \mathrm{E}-5-8.24 \mathrm{E}-5 \mathrm{~ms}^{-1}$ is significantly higher than both the simulation results with a saturated hydraulic conductivity of $k_{s}=1.85 \mathrm{E}-6 \mathrm{~ms}^{-1}$ (Tab. 5; No. I, IV) and the laboratory data with $k_{s}<6.0 \mathrm{E}-8 \mathrm{~ms}^{-1}$ (Tab. 1). Furthermore, the coloured flow paths show that a large part of infiltrating water flowed along fine roots (bio pores) and across aggregate surfaces (interaggregate pores) as displayed in Fig. 5.

In studies on the infiltration rate of dike covers on sea and estuary dikes at the North Sea TEMMLER [18] found out that the in-situ infiltration rates $\left(1.04 \mathrm{E}-6 \mathrm{~ms}^{-1}\right.$ to $6.02 \mathrm{E}-5 \mathrm{~ms}^{-1}$ ) are frequently very high. He also could not find any correlation between infiltration characteristics and geotechnical properties (e.g. clay content or liquid limit), however, a dependency to soil texture could be determined.

To simulate preferential flow paths, bimodal SWRCs [15] and dual porosity approaches [16, 17] can be used. For this reason, a final simulation is conducted in which

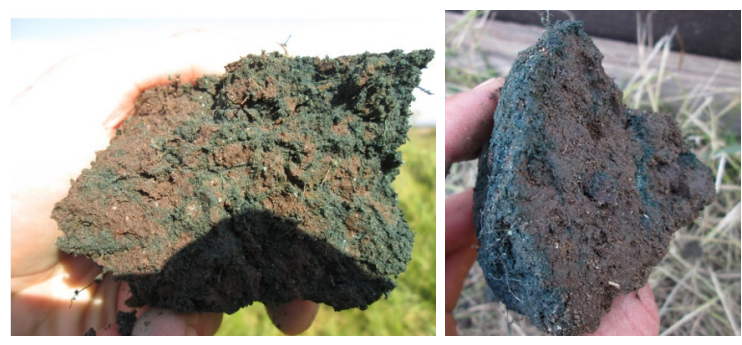

Fig. 5 M2 soil sample with coloured matrix and finger flow (bio pores and inter-aggregate pores) obtained by double infiltration test using methylene blue as tracer.

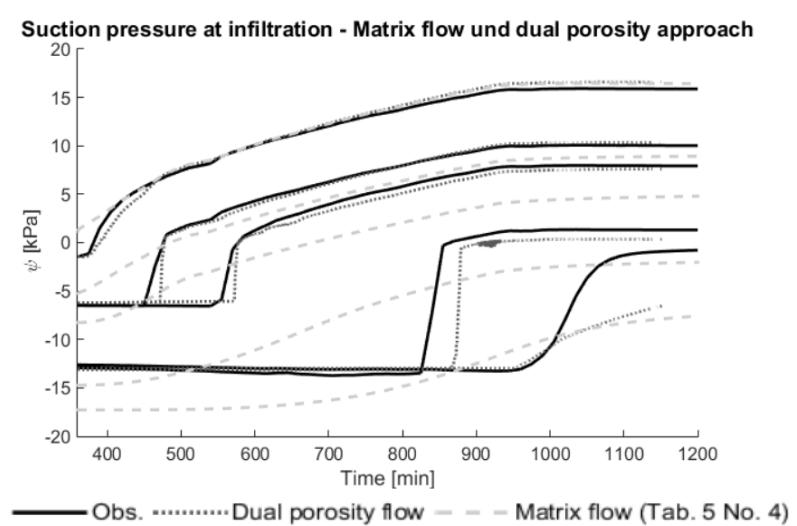

Fig. 6 Recorded and simulated suction pressure during the dike infiltration using matrix- and dual porosity approaches.

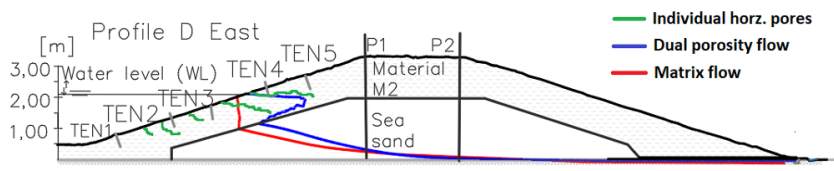

Fig. 7 Calculated phreatic lines for matrix flow (Tab. 5 No. 4) and dual porosity flow on cross-section D (minute 790).

the soil matrix $\left(k_{s}\right)$ and a horizontal macro-pore flow (using HAGEN-POISEUILLE's law in discrete feature elements) are computed simultaneously for material M2. The introduction of this elemental flow heavily complicates the model setup (increasing computation time) and tends to cause numerical oscillation errors in some cases. Therefore, an automatic calibration is not suitable and the parameters are adjusted manually. Although a global minimum cannot be found with certainty, the dual porosity approach considerably improves the model fitting for the tensiometer data (Fig. 6) and enables the reduction of the model error for all OBFs.

As illustrated in Fig. 6, the dual porosity approach shows a very close accordance to the recorded observation data. Using this approach, the cover layer starts to saturate immediately and very fast as soon as the water level exceeds the vertical sensor position and the deviation under saturation is reduced. Compared to the matrix flow, the material starts to saturate earlier but slower. The deviation under saturation remains higher.

The calculated phreatic line for the matrix flow and the dual porosity flow are illustrated in Fig. 7. The wetting front of the dual porosity model shifts horizontally inside the cover layer but the hydraulic head in $\mathrm{P} 1$ and $\mathrm{P} 2$ remains comparable.

\section{Conclusions}

The analysis shows that the use of laboratory data to numerically simulate the physical infiltration processes on the Rostock research dike with sufficient accuracy is difficult. The lab parameters differ considerably to the best fit model parameters and do also not represent the properties in situ.

It was found out that an assumption of unimodal SWRCs and an unsaturated/ saturated matrix flow does 
not lead to an optimum solution. In this case, the model response is comparable to a PARETO problem, in which an optimum is always a compromise between many solutions and no single parameter set can be found for a suitable global minimum of all objectives.

Regarding the infiltration behaviour referred on suction pressure data, it is hard to draw information about infiltration and hydraulic properties using a matrix flow concept. In this case, very absorbent SWRC fitting values in combination with high permeability coefficients are leading to an immediate reaction of soil moisture. But a variation of the maximum hydraulic permeability affects the hydraulic head and rate budget model fitting. A proper solution cannot be found in changing the unsaturated flow model and its fitting parameters as it is clear that the unsaturated water flow never exceeds the maximum saturated water flow.

It is shown that the best fit in this study can be obtained using a dual porosity approach, in which a matrix flow with very low hydraulic conductivity and a horizontal pore flow exist simultaneously. In this case, the suction pressure behaviour is primarily affected by an individual macro, inter-aggregate and bio-pore system that may be caused by comparably low compaction during installation in the research dike, plant growth and desiccation cracks. These pores are not represented in the approaches of unsaturated matrix flow models if they are formulated by a unimodal pore size distribution and therefore, they should be excluded from considerations of hysteresis effects.

The combination of low permeability matrix flow and porosity flow is considered as the effective permeability and governs both the hydraulic head in the dike core and the budget rate on the drainage composite. This information is extremely relevant for engineering purposes (e.g. in design consideration and stability calculation).

Regarding the recorded drainage rate in the steady state condition $\left(Q=3.13 \mathrm{E}-6 \mathrm{~m}^{3} \mathrm{~s}^{-1} \mathrm{~m}^{-1}\right)$ a relative permeability of approximately $4.98 \mathrm{E}-7 \mathrm{~ms}^{-1}$ for the cover layer can be re-calculated. Considering uncertainties of drainage water collection, uncertainties of the tipping counter measurement method and transformation into filter conductivity, this value shows a closer relationship to identified $k_{s}$-value of Tab 5 No. $1\left(k_{s}=1.85 \mathrm{E}-6 \mathrm{~ms}^{-1}\right)$. Finally, the double-ring infiltration data of $2.88 \mathrm{E}-5$ to $8.24 \mathrm{E}-5 \mathrm{~ms}^{-1}$ and the laboratory data obtained from undisturbed soil sample $k_{s} \approx 5 \mathrm{E}-8 \mathrm{~ms}^{-1}$ lead to an over and under estimation on the infiltration respectively.

For further studies on the infiltration behaviour on the Rostock research dike, the suction pressure data should be neglected to reduce the number of variables.

\section{References}

1. F. Saathoff, S. Cantré, Z. Sikora, South Baltic guideline for the application of dredged materials, coal combustion products and geosynthetics in dike construction (2015)
2. G. Morscheck, A. Lemke, M. Henneberg, Proc. of the S. Baltic Conf. on Dredged Materials in Dike Construction, (2014)

3. R. Weisz, Tagungsband 2 Rost. Baggergut Sem., Rostock (2009)

4. E. Nischke, S. Cantré, F. Saathoff, Proc. of the S. Baltic Conf. on Dredged Materials in Dike Construction (2014)

5. H.-J. G. Dierch, FEFLOW: Finite element modelling of flow, mass and heat transport and fractured media, Berlin (2014)

6. J.A. Vrugt, Multi-criteria optimization using the AMALGAM software package: Theory, concepts and MATLAB implementation, Uni. of Irvine, (2016)

7. F. Saathoff, S. Cantré, Eng. Struc. and Techn. (2013)

8. M.T. VanGenuchten, F.J. Leij, S.R. Yates, The RetC code for quantifying hydraulic functions of unsaturated soils, S. Kerr envir. Res. Lab. (1991)

9. R. Haselsteiner, Deiche an Fließgewässern und ihre Durchsickerung [phd] TU Munich (2007)

10. K. Liu, P.J. Vardon, P. Arnold, IOP Conf. Series Earth a. Environm. Sci. 26 (2015)

11. M. D. Sleep, Analysis of Transient Seepage through levees [phd] (2011)

12. G. Pevlakis, L. Barden, J. Soil Sci 23,3 pp. 351-316 (1973)

13. H.-P. Blume, F. Scheffer, P. Schachtschabel, Lehrbuch der Bodenkunde (2016)

14. M. Tuller, D. Or, Water retention and characteristic curve (2005)

15. R. Zhang, M.T. Van Genuchten, Soil Sci.. 158,2 pp. 77-85 (1994)

16. R. Vogel, H. H. Gerke, R. Zhang, M. T. Van Genuchten, J. of. Hydr. 238. pp. 78-89 (2000)

17. R. Ludwig, H. H. Gerke, O. Wendroth, J. of. Hydr. 215. pp. 135-152 (1999)

18. H. Temmler, Fachausschuss Küstenschutzwerke: Laufende und künftige Projekte“ (2009) 